\title{
Epilepsy as a health problem among school children in Turaif, Northern Saudi Arabia, 2017
}

Mahmoud Mohammed Alsharif ${ }^{1}$, Nagah Mohamed Abo el-Fetoh ${ }^{2}$, Gihan Yousef Alii ${ }^{4}$, Khulud Falah Alanazi ${ }^{1}$, Anfal Nayir Alanazi ${ }^{1}$, Ohud FalahAlanazi ${ }^{3}$, Maha Hazzaa Alshalan ${ }^{3}$, Zuhur Dhaher Alfuhigi ${ }^{3}$, Anwar Eid Alruwaili ${ }^{3}$, Reem Sebeh Alhazmi ${ }^{3}$, Ajaweed Saud Muharrab Alruwaili ${ }^{3}$, Tariq Mozil Aquab Alanizy ${ }^{3}$, Jazzaa Hammad Alshammari ${ }^{3}$, Alwaleed Oqab Altimyat ${ }^{3}$, Muharib Mana Muhaylan Alshammari ${ }^{3}$

${ }^{1}$ Intern, Faculty of Medicine, Northern Border University, Arar, Saudi Arabia

${ }^{2}$ Associate Professor, Community Medicine Department, Faculty of medicine, Northern Border University, Arar, Saudi Arabia

${ }^{3}$ Student, Faculty of Medicine, Northern Border University, Arar, Saudi Arabia

${ }^{4}$ Lecture of Pediatric, Pediatric Department, Sohag College of Medicine, Sohag University, Eygpt

Type of article: Original

\begin{abstract}
Background: Epilepsy is the most common serious neurological disorder and is one of the world's most prevalent non-communicable diseases. There are no recently published data on the prevalence of epilepsy in school children in Northern Saudi Arabia.

Objective: This study was conducted to determine the prevalence of epilepsy and to show some of its risk factors in school children and adolescents (6-18 years) in Turaif city, Northern Saudi Arabia.

Methods: This, population-based, cross-sectional study was conducted in Turaif city, over a 6-month period, from July 2016 to January 2017. It included pupils aged 6 to 18 years in all primary, preparatory and secondary schools in Turaif city. Multi-stage sampling was employed. A designated structured questionnaire was completed for each patient and included the patient's history, clinical examination, investigations and medications. Data were analyzed by SPSS version 16, using Chi-Squared test and descriptive statistics.

Results: Out of 1,230 children, 66 (5.5\%) had epilepsy; $68.2 \%$ of them were males and $31.8 \%$ females $(\mathrm{p}=0.000)$. Consanguinity between parents plays a significant role where $59.1 \%$ of cases had parents who were cousins $(\mathrm{p}=0.000)$. Family history also had a significant effect as $68.2 \%$ of cases had epilepsy cases in their families $(\mathrm{p}=0.000)$.

Conclusion: Epilepsy prevalence among school children (6-18 years) in Turaif city is higher in males than females. Consanguinity and positive family history are important factors. Decision makers must take effective steps to limit the causes and risk factors of the problem.
\end{abstract}

Keywords: Prevalence, Epilepsy, Turaif, Northern border, Saudi Arabia

\section{Introduction}

Epilepsy is a group of neurological disorders characterized by epileptic seizures $(1,2)$. It is the commonest chronic, recurrent neurological childhood disease, and has become a major public health problem $(3,4)$. Very little is known about the exact mechanism of epilepsy (5), however, a little is understood regarding its cellular and network mechanisms. During a period of epilepsy, there is a decrease in the resistance to fire the excitatory neurons. This may be because of changes in ion channels or because of the inhibitory neurons failing to function correctly. This then results in development of seizures from a specific area of the brain, known as a "seizure focus" (6). Cases can occur as the result of brain injury, brain tumor, infections of the brain, stroke, and birth defects, which occur through a process called epileptogenesis (7-9). However, how the brain shifts into the activity of a seizure with its excessive synchronization remains unclear $(10,11)$. Both genetic and acquired causes such as serious brain trauma, tumors stroke, and complications resulting from previous infection, can be the cause of epilepsy, with interaction of these

\section{Corresponding author:}

Mahmoud Mohammed Alsharif, Faculty of Medicine, Northern Border University, Arar, Saudi Arabia.

Tel: +966.500976100, Email: mbbs.ms@outlook.com

Received: June 10, 2017, Accepted: July 11, 2017, Published: August 2017

iThenticate screening: July 11, 2017, English editing: August 10, 2017, Quality control: August 12, 2017

(C) 2017 The Authors. This is an open access article under the terms of the Creative Commons Attribution-NonCommercialNoDerivs License, which permits use and distribution in any medium, provided the original work is properly cited, the use is non-commercial and no modifications or adaptations are made. 
factors in many cases (12). The cause of epilepsy is unknown in about $60 \%$ of all cases (13). Valid and reliable information is needed concerning the prevalence of epilepsy and its natural course and causes, to better develop the approach to epilepsy treatment, analyze the efficiency of therapeutic strategies and, more importantly, determine methods for the prevention of its development. Epidemiological studies can provide such information $(4,14,15)$. Many studies have discussed epilepsy among school children. A study in Turkey found that among 1,625 primaryschool students aged 6 to14 years, twenty-two children were diagnosed as epileptic. In male patients, the point prevalence of active epilepsy was $4.9 / 1000$, and in female patients, it was $12.4 / 1000$, representing a total of 8.6/1000. In males, the cumulative prevalence was 11.0/1000, and in females, it was $16.1 / 1000$, representing a total of 13.5/1000. Febrile convulsions, history of head trauma, family history of epilepsy, antenatal/postnatal problems, serious maternal illness during pregnancy, and a history of neonatal jaundice all had a statistically significant relation to the development of epilepsy (16).In another study in Kayseri (17), it was revealed that in males the raw prevalence of epilepsy was $9 / 1000$, in females it was $6 / 1000$ and in both groups together, it was $8 / 1000$. Prevalence of active epilepsy in males was $7 / 1000$, in females it was $4 / 1000$, and in both groups together it was $6 / 1000$. It was found that risk of epilepsy increased 2.6 times due to premature birth, and risk of epilepsy due to average and poor family income levels increased 3.3 and 1.6 times, respectively. Risk of epilepsy increased 15.1 times due to history of febrile convulsion. There are no recently published data on the prevalence of epilepsy in school children in Northern Saudi Arabia. This study was conducted to determine the prevalence of epilepsy and to show some of its risk factors in school children and adolescents (6 to18 years) in Turaif city, Northern Saudi Arabia.

\section{Material and Methods}

\subsection{Setting and design}

This, population-based, cross-sectional study was conducted in Turaif city, over a six-month period, from July 2016 to January 2017. The study was conducted in Turaif city, the capital of the Northern area of Saudi Arabia. Within the city, government and private schools were distributed according to population density and demand. It included pupils aged 6 to 18 years in all primary, preparatory and secondary schools in Turaif city. It did not include schools for children with special needs. The study was undertaken in two phases: the first consisted of interviews by authors and field workers to identify pupils with possible epilepsy, and the second phase comprised validation, medical evaluation and management by the pediatric neurologists.

\subsection{Selection criteria}

Inclusion criteria was all school children in Turaif city (public and private schools), and exclusion criteria was all schools for children with special needs.

\subsection{Sampling}

Multi-stage sampling was employed. First, simple random sampling was used to draw a cluster of four clusters out of seven in the city. Information on the number of public and private schools and pupils was obtained from the Ministry of Education, Northern Saudi Arabia. The sample frame in the selected localities consisted of public and private schools. A sample size of 1,230 students was determined with a $95 \%$ confidence interval, $0.25 \%$ margin of error, a population size of 10,285 students and a design effect of 1.5 to account for the multi-stage sampling design, given the increase in variance arising from the cluster. To calculate the sample size, the population prevalence of epilepsy in school-age children was assumed to be $50 \%$. Assuming an average of 303 students per school, 5 schools were drawn from a sample frame of 35 schools using a stratified random sampling technique. The sample was stratified by locality, school type (public or private) and gender. The sample was distributed among the four localities in proportion to the total number of schools in each. The schools in each stratum were selected by simple random sampling using random digit tables.

\subsection{Data collection}

Before the study commenced, all data collectors were briefed during a one-day training session. The data collectors were junior doctors and final year's medical students in addition to field supervisors from the Department of Community Medicine, Faculty of Medicine, and Northern Border University. The main aim of the training was to improve reliability and consistency. A confidential letter was sent to the parents of each case identified, explaining the aims of the study and providing information on the research group and the kind of help that would be offered to the pupil. Parents who consented to their child's participation in the study were asked to contact the study group by telephone or email. All nominated children attended the Outpatient Department for further assessment including history-taking, clinical examination and EEG (when required) by a pediatric neurologist. A structured questionnaire was completed for each patient and included the patient's history, clinical examination, investigations and 
http://www.ephysician.ir

medications. An EEG was requested for every patient who was clinically suspected of having had an epileptic seizure. Patients were classified according to the International League against Epilepsy classification, and were managed accordingly (18).

\subsection{Ethical considerations}

Approval was granted by the Northern Border University Research and Ethics Committee, The Ministry of Health and the Ministry of Education in Arar city. Verbal consent was obtained from headmasters after the aims of the study had been explained. Consent was also obtained from the parents of the study pupils. Confidentiality was ensured at all stages.

\subsection{Statistical analysis}

Data were compiled and analyzed using SPSS version16 (SPSS Inc., Chicago, Illinois, USA) and results were analyzed with frequencies and Chi-squared test as appropriate. P-value were set at 5\%.

\section{Results}

Table 1 illustrates the Socio-demographic characteristics of studied children, Turaif, Northern Saudi Arabia, 2017.

The findings showed that male to female ratio was 81.2 to 18.8 , Saudi to non-Saudi ratio 90 to 10 , mothers aged 20 to 39 years constituted $50.5 \%$ and $46.3 \%$ aged 40 to 60 years.

Table 1. Socio-demographic characteristics of studied children, Turaif, Northern Saudi Arabia, 2017.

\begin{tabular}{|c|c|c|c|}
\hline \multicolumn{2}{|l|}{ Parameter } & Frequency $(n=1230)$ & $\%$ \\
\hline \multirow{3}{*}{ Child's age group (years) } & $6-12$ & 501 & 40.7 \\
\hline & $13-15$ & 495 & 40.2 \\
\hline & $16-18$ & 234 & 19.0 \\
\hline \multirow[t]{2}{*}{ Sex } & Male & 999 & 81.2 \\
\hline & Female & 231 & 18.8 \\
\hline \multirow[t]{3}{*}{ Age (years) } & $<18$ & 126 & 8.0 \\
\hline & $18-50$ & 1362 & 86.9 \\
\hline & $>50$ & 79 & 5.0 \\
\hline \multirow{2}{*}{ Nationality } & Saudi & 1107 & 90.0 \\
\hline & Non-Saudi & 123 & 10.0 \\
\hline \multirow[t]{3}{*}{ Mother's age group (years) } & $20-39$ & 621 & 50.5 \\
\hline & $40-59$ & 570 & 46.3 \\
\hline & $\geq 60$ & 39 & 3.2 \\
\hline \multirow[t]{5}{*}{ Mother's education } & Primary & 198 & 16.1 \\
\hline & Preparatory & 252 & 20.5 \\
\hline & Secondary & 237 & 19.3 \\
\hline & University & 381 & 30.0 \\
\hline & Illiterate & 162 & 13.2 \\
\hline \multirow[t]{2}{*}{ Mother's work } & Working & 312 & 25.4 \\
\hline & Not working & 918 & 74.6 \\
\hline \multirow[t]{3}{*}{ Father's age group (years) } & $20-39$ & 153 & 12.4 \\
\hline & $40-59$ & 942 & 76.6 \\
\hline & 60 and above & 135 & 11.0 \\
\hline \multirow[t]{5}{*}{ Father's education } & Primary & 237 & 19.3 \\
\hline & Preparatory & 162 & 13.2 \\
\hline & Secondary & 324 & 26.3 \\
\hline & University or more & 272 & 30.3 \\
\hline & Illiterate & 135 & 11.0 \\
\hline \multirow[t]{4}{*}{ Consanguinity } & Cousins & 453 & 36.8 \\
\hline & Relatives of the same family & 372 & 30.2 \\
\hline & Non-relatives of the same family & 105 & 8.5 \\
\hline & No relation & 300 & 24.4 \\
\hline \multirow[t]{2}{*}{ Family history of epilepsy } & Yes & 162 & 13.2 \\
\hline & No & 1068 & 86.8 \\
\hline \multirow[t]{2}{*}{ Other chronic diseases } & Yes & 51 & 4.1 \\
\hline & No & 1179 & 95.9 \\
\hline
\end{tabular}


Primary educated constituted $16.1 \%, 20.5 \%$ had preparatory education, $30.0 \%$ university and more and $13.2 \%$ were illiterate, working to non-working mother ratio was 25.4 to 74.6 . As regards consanguinity, $36.8 \%$ were cousins, $30.2 \%$ relatives of the same family, $8.5 \%$ non-relatives of the same family and in $24.4 \%$ there was no relation. Family history of epilepsy was found in $13.2 \%$ of the studied children. Table 2 illustrates the prevalence of epilepsy among studied children in Northern Saudi Arabia, 2016/2017. The table showed that $60(5.5 \%)$ of the total $(1,230)$ studied cases had epilepsy. From the 66 epileptic children, $22.7 \%$ had one fit per month, $68.2 \%$ had $2-5$ fits, and $9.1 \%$ had more than 5 fits per month. In total, $90.9 \%$ had regular treatment. The majority $(63.6 \%)$ had history of hospital admission due to epilepsy. As regards the response to treatment, $68.2 \%$ felt better, $27.3 \%$ had no apparent response but $4.5 \%$ became worse in spite of the treatment. Table 3 illustrates the relationship between epilepsy and epilepsy related characteristics among studied children in northern Saudi Arabia in 2017. The table showed that 45 $(68.2 \%)$ of the cases were males and about half this number $21(31.8 \%)$ were females $(p=0.000)$. Child's age in years and consanguinity between parents were significantly associated with the development of epilepsy where $59.1 \%$ of epilepsy patients who participated in the current study had parents who were cousins and $13.6 \%$ were nonrelatives of the same family and only $22.7 \%$ of cases had no relation between their parents $(\mathrm{p}=0.000)$. Family history of epilepsy was significantly associated with the development of it where $68.2 \%$ of epilepsy patients who participated in the current study had positive family history while about half of them (31.8\%) had negative family history $(\mathrm{p}=0.000)$. Mother and father age groups were also significantly associated with the development of epilepsy $(\mathrm{p}=0.000)$. More than half $(54.5 \%)$ of cases had working mothers $(\mathrm{p}=0.000)$.

Table 2. Prevalence of epilepsy among studded children, northern Saudi Arabia, 2017

\begin{tabular}{|l|l|l|l|}
\hline Variable & $\mathrm{n}$ & $\%$ \\
\hline Epilepsy $(\mathrm{n}=1230)$ & Yes & 66 & 5.5 \\
\cline { 2 - 4 } & No & 1164 & 94.5 \\
\hline Frequency of fits per month $(\mathrm{n}=66)$ & One time or less & 15 & 22.7 \\
\cline { 2 - 4 } & $2-5$ & 45 & 68.2 \\
\cline { 2 - 4 } & $>5$ & 6 & 9.1 \\
\hline \multirow{2}{*}{ Treatment of epilepsy $(\mathrm{n}=66)$} & Yes & 60 & 90.9 \\
\cline { 2 - 4 } & No & 6 & 9.1 \\
\hline \multirow{2}{*}{ Regularity of treatment $(\mathrm{n}=66)$} & Regular & 60 & 90.9 \\
\cline { 2 - 4 } & Irregular & 6 & 9.1 \\
\hline \multirow{2}{*}{ History of hospital admission $(\mathrm{n}=66)$} & Yes & 42 & 63.6 \\
\cline { 2 - 4 } & No & 24 & 36.4 \\
\hline Response to treatment $(\mathrm{n}=66)$ & Better & 45 & 68.2 \\
\cline { 2 - 4 } & Worse & 3 & 4.5 \\
\cline { 2 - 4 } & Same & & 27.3 \\
\hline
\end{tabular}

Table 3. Relationship between epilepsy and epilepsy related characteristics among studded children, northern Saudi Arabia, 2017.

\begin{tabular}{|l|l|l|}
\hline Parameter & Chi-squared & $\mathrm{p}$-value \\
\hline Sex & 6.81 & 0.006 \\
\hline Child's age group in years & 5.79 & 0.055 \\
\hline Consanguinity between parents & 26.81 & 0.00 \\
\hline Family history of epilepsy & 116.4 & 0.000 \\
\hline Mother's age group in years & 0.503 & 0.000 \\
\hline Father's age group in years & 13.41 & 0.001 \\
\hline Mother's work & 14.86 & 0.000 \\
\hline Previous abdominal surgery & 1.005 & 0.00 \\
\hline Previous abdominal trauma & 38.533 & 0.00 \\
\hline Family history of hernia & 23.995 & 0.00 \\
\hline Grand multipara (repeated pregnancy more than 5 times) & 38.523 & 0.000 \\
\hline
\end{tabular}

\section{Discussion}

Epilepsy is the most common serious neurological disorder and is one of the world's most prevalent noncommunicable diseases. The condition affects approximately 50 million people. Around 40 million of them living in developing countries (19). Efforts to provide treatment were successful, which has highlighted the importance of using community-based methods (20). Epilepsy is more prevalent in older people $(21,22)$. Though, in developing 
nations, it is more prevalent in older children and young adults, due to differences in the regularity of the fundamental causes (23). Prevalence rates of active epilepsy in developing nations range from 5 to 10 per 1000 people (24-26). There are no recently published data on the prevalence of epilepsy in school children in Northern Saudi Arabia. So, this study was conducted to determine the prevalence of epilepsy and to show some of its risk factors in school children in Turaif city, Northern Saudi Arabia. In our study, 66 children (5.5\%) out of 1,230 had epilepsy; $45(68.2 \%)$ were males and $21(31.8 \%)$ were females. The prevalence of epilepsy in studies to date exhibits a wide variation ranging between $2.8 / 1000$ and 44/1000 (39-60). A study of neurological disorders in Saudi Arabia (27) found that epilepsy was prevalent with a percent of (6.54\%). The prevalence (per 1000 population) in many countries were 9.8 in Pakistan (28), 6.7-8 in different regions of Ecuador (29), 5.7-6.8 in USA (30, 31), 5.3 in Nigeria (32), 4.8 in the Peoples' Republic of China (33), 4.8 among the Parsi community in India (34) and 3.6 in Tunisia (35). In a study by W. Allen et al. (36), the incidence of epilepsy (recurrent unprovoked seizures) in children and adolescents seems relatively consistent across all populations studied, ranging from 50 to 100/100,000. The highest incidence of epilepsy is in the first year of life. In our study, $45.5 \%$ of the cases were 6 to 12 years and there was highly significant association between age and sex and prevalence of epilepsy $(\mathrm{p}=0.000)$. Another study found that the median age of onset of seizures was 8 years (37). Another study found that the mean age of subjects diagnosed with epilepsy was $11.94 \pm 2.99$ years, but they found no significant difference between males and females in terms of epilepsy $(\mathrm{p}=0.098)(17)$. Other studies have reported a 1.4 -fold greater prevalence of epilepsy in males compared to females $(39,40)$. Regarding risk factors for epilepsy, our results show that about $(68.2 \%)$ had relatives of the same family with history of epilepsy, and there was a significant association between family history and epilepsy $(\mathrm{p}=0.000)$. A Prischich et al. study reported that there was a significant association between family history and epilepsy (38). Another study's analysis of epilepsy case risk factors revealed positive family history in $40 \%$ of epilepsy cases (17). Consanguinity between parents was significantly associated with the development of epilepsy where $59.1 \%$ of epilepsy patients who participated in the current study had parents who were cousins and $13.6 \%$ were non-relatives of the same family and only $22.7 \%$ of cases had no relation between their parents $(\mathrm{p}=0.000)$. This agreed with the results with the twin studies of Lennox $(41,42)$ that found a genetic link to epilepsy. Further population studies revealed an increased familial clustering of epilepsy among first degree and to a lesser degree, second degree relatives (43).

\section{Conclusions}

Epilepsy is a common neurological disorder in this part of Saudi Arabia, its prevalence among school children (6-18 years) is $5.5 \%$, which is higher in males than in females. It is associated with consanguinity and positive family history. Decision makers must take effective steps to limit the causes and risk factors of the problem. Adequate and proper prenatal care aimed at avoiding problems during pregnancy and perinatal measures could reduce complications that may result in epilepsy. Strengthening of the health systems to include information about the risk factors for Epilepsy in their outreach programs could reduce the prevalence of epilepsy in Turaif, Northern Saudi Arabia.

\section{Acknowledgments:}

The success and final outcome of this work required the support and assistance of many people and we are fortunate to have gotten this throughout the completion of the work. We appreciate the support and cooperation of Abd alRahman ibn 'Awf primary school in Turaif city. Our thanks also go to Nour Homoud Alanazi, Yasir Wadi Alanazi, Arwa Nughaymish Alanazi, Amjad Hamoud Alruwaili and Anwar Matar Alsulobi (Students, Faculty of Medicine NBU) for their help in different steps of the research.

\section{Conflict of Interest:}

There is no conflict of interest to be declared.

\section{Authors' contributions:}

All authors contributed to this project and article equally. All authors read and approved the final manuscript.

\section{References:}

1) Chang BS, Lowenstein DH. Epilepsy. N Engl J Med. 2003; 349(13): 1257-66. doi: 10.1056/NEJMra022308. PMID: 14507951.

2) Fisher RS, Acevedo C, Arzimanoglou A, Bogacz A, Cross JH, Elger CE, et al. ILAE official report: a practical clinical definition of epilepsy. Epilepsia. 2014; 55(4): 475-82. doi: 10.1111/epi.12550. PMID: 24730690 . 
3) Hauser WA, Banerjee PE. Epidemiology of epilepsy in children. Pediatric epilepsy. 3rd ed. New York; Demos Medical Publishing; 2008: 147-64.

4) Yeni, SN. Epilepsi İnsidansı, Prevalansı ve Risk Faktörleri. Epilepsi. İstanbul: Nobel Tıp Kitapevleri; 2008: $65-73$.

5) Noebels J, Avoli M, Rogawski M, Olsen R, Delgado-Escueta A. Jasper's Basic Mechanisms of the Epilepsies. Oxford University Press. 2012: 466-70. ISBN 9780199746545.

6) Epilepsy, Fact sheet. WHO. 2016.

7) Hammer GD, McPhee SJ. Pathophysiology of disease: an introduction to clinical medicine. 6th ed. New York: McGraw-Hill Medical; 2010. ISBN 978-0-07-162167-0.

8) Goldberg EM, Coulter DA. Mechanisms of epileptogenesis: a convergence on neural circuit dysfunction. Nat Rev Neurosci. 2013; 14 (5): 337-49. doi: 10.1038/nrn3482. PMID: 23595016, PMCID: PMC3982383.

9) Le Van Quyen M, Navarro V, Martinerie J, Baulac M, Varela FJ. Toward a Neurodynamical Understanding of Ictogenesis. Epilepsia. 2003; 44(Suppl 12): 30-43. doi: 10.1111/j.00139580.2003.12007.x. PMID: 14641559.

10) Lopes da Silva F, Blanes W, Kalitzin SN, Parra J, Suffczynski P, Velis DN. Epilepsies as Dynamical Diseases of Brain Systems: Basic Models of the Transition Between Normal and Epileptic Activity. Epilepsia. 2003; 44(Suppl 12): 72-83. doi: 10.1111/j.0013-9580.2003.12005.x. PMID: 14641563.

11) Berkovic SF, Mulley JC, Scheffer IE, Petrou S. Human epilepsies: interaction of genetic and acquired factors. Trends Neurosci. 2006; 29(7): 391-7. doi: 10.1016/j.tins.2006.05.009. PMID: 16769131.

12) National Clinical Guideline Centre. The Epilepsies: The diagnosis and management of the epilepsies in adults and children in primary and secondary care. National Institute for Health and Clinical Excellence. 2012: 21-8.

13) Epilepsy, Fact Sheets. WHO. 2012.

14) ILAE Commission Report. The epidemiology of the epilepsies: future directions. International League Against Epilepsy. Epilepsia. 1997; 38: 614-8. doi: 10.1111/j.1528-1157.1997.tb01148.x. PMID: 9184609.

15) Guidelines for epidemiologic studies on epilepsy. Commission on Epidemiology and Prognosis, International League Against Epilepsy. Epilepsia. 1993; 34(4): 592-6. doi: 10.1111/j.15281157.1993.tb00433.x. PMID: 8330566.

16) Huseyinoglu N, Ozben S, Arhan E, Palanci Y, Gunes N. Prevalence and risk factors of epilepsy among school children in eastern Turkey. Pediatr Neurol. 2012; 47(1): 13-8. doi: 10.1016/j.pediatrneurol.2012.04.007. PMID: 22704010.

17) Canpolat M, Kumandas S, Poyrazoglu HG, Gumus H, Elmali F, Per H. Prevalence and risk factors of epilepsy among school children in Kayseri City Center, an urban area in Central Anatolia, Turkey. Seizure. 2014; 23(9): 708-16. doi: 10.1016/j.seizure.2014.05.012. PMID: 24939524.

18) Berg AT, Berkovic SF, Brodie MJ, Buchhalter J, Cross JH, van Emde Boas W, et al. Revised terminology and concepts for organization of seizures and epilepsies: report of the ILAE commission on classification and terminology, 2005-2009. Epilepsia. 2010; 51: 676-85. doi: 10.1111/j.1528-1167.2010.02522.x. PMID: 20196795.

19) The Global Campaign against Epilepsy. Geneva: World Health Organization: 2000.

20) Scott RA, Lhatoo SD, Sander JW. The treatment of epilepsy in developing countries: where do we go from here? Bull World Health Organ. 2001; 79(4): 344-51. PMID: 11357214, PMCID: PMC2566404.

21) Brodie MJ, Elder AT, Kwan P. Epilepsy in later life. Lancet neurology. 2009; 8(11): 1019-30. doi: 10.1016/S1474-4422(09)70240-6. PMID: 19800848.

22) Holmes GL, Browne TR. Handbook of epilepsy. 4th ed. Philadelphia: Lippincott Williams \& Wilkins; 2008: 7. ISBN 978-0-7817-7397-3.

23) Newton CR, Garcia HH. Epilepsy in poor regions of the world. Lancet. 2012; 380(9848): 1193-201. doi: 10.1016/S0140-6736(12)61381-6.

24) Bertolote JM. Epilepsy as a public health problem. Role of the World Health Organization and of the cooperation between WHO and non-governmental organizations. Trop Geogr Med. 1994; 46(3 Suppl): S28-30. PMID: 7974766.

25) Aziz H, Güvener A, Akhtar SW, Hasan KZ. Comparative epidemiology of epilepsy in Pakistan and Turkey: population-based studies using identical protocols. Epilepsia. 1997; 38: 716-22. doi: 10.1111/j.1528-1157.1997.tb01242.x. PMID: 9186255.

26) Gourie-Devi M, Satischandra P, Gururaj G. Report of national workshop on public health aspects of epilepsy for senior health personnel of state health departments in India. Annals of Indian Academy of Neurology. 1999; 2: 43-8. 
27) al Rajeh S, Bademosi O, Ismail H, Awada A, Dawodu A, al-Freihi H, et al. A Community Survey of Neurological Disorders in Saudi Arabia: The Thugbah Study. Neuroepidemiology. 1993; 12(3): $164-78$. doi: 10.1159/000110316. PMID: 8272177.

28) Aziz H, Ali SM, Frances P, Khan MI, Hasan KZ. Epilepsy in Pakistan. A population based epidemiologic study. Epilepsia. 1994; 35: 950-8. doi: 10.1111/j.1528-1157.1994.tb02539.x. PMID: 7925166.

29) Placencia M, Shorvon SD, Paredes V, Bimos C, Sander JW, Suarez J. Epileptic seizures in an Andean region of Ecuador. Incidence prevalence and regional variations. Brain. 1992; 115: 771-82. doi: 10.1093/brain/115.3.771. PMID: 1628201.

30) Haerer AF, Anderson DW, Schoenberg BS. Prevalence and clinical features of epilepsy in a biracial United States population. Epilepsia. 1986; 27: 66-75. doi: 10.1111/j.1528-1157.1986.tb03503.x. PMID: 3948820.

31) Hauser WA, Kurland LT. The epidemiology of epilepsy in Rochester, Minnesota, 1935 through 1967. Epilepsia. 1975; 16: 1-66. doi: 10.1111/j.1528-1157.1975.tb04721.x. PMID: 804401.

32) Li SC, Schoenberg BS, Wang CC, Cheng XM, Zhou SS, Bolis CL. Epidemiology of epilepsy in urban areas of the Peoples' Republic of China. Epilepsia. 1985; 26: 391-4. doi: 10.1111/j.15281157.1985.tb05669.x. PMID: 4043008.

33) Bharucha NE, Bharucha EP, Bharucha AE, Bhise AV, Schoenberg BS. Prevalence of epilepsy in the Parsi community of Bombay. Epilepsia. 1988; 29: 111-115. doi: 10.1111/j.1528-1157.1988.tb04405.x. PMID: 3258234.

34) Attia-Romdhane N, Mrabet A, Ben Hamida M. Prevalence of epilepsy in Kelibia, Tunisia. Epilepsia. 1993; 34: 1028-32. doi: 10.1111/j.1528-1157.1993.tb02129.x. PMID: 8243352.

35) Annegers JF, Grabow JD, Groover RV, Laws ER Jr, Elveback LR, Kurland LT. Seizures after head trauma: a population study. Neurology. 1980; 30: 683-9. doi: 10.1212/WNL.30.7.683. PMID: 7190235.

36) Hauser WA. The Prevalence and Incidence of Convulsive Disorders in Children. Epilepsia. 1994; 35 Suppl 2: S1-6. PMID: 8275976.

37) Ae-Ngibise KA, Akpalu B, Ngugi A, Akpalu A, Agbokey F, Adjei P, et al. Prevalence and risk factors for Active Convulsive Epilepsy in Kintampo, Ghana. Pan Afr Med J. 2015; 21: 29 . doi: 10.11604/pamj.2015.21.29.6084. PMID: 26401223, PMCID: PMC4561141.

38) Prischich F, De Rinaldis M, Bruno F, Egeo G, Santori C, Zappaterreno A, et al. High prevalence of epilepsy in a village in the Littoral Province of Cameroon. Epilepsy Res. 2008; 82(2-3): 200-10. doi: 10.1016/j.eplepsyres.2008.09.004. PMID: 18976884.

39) Sangrador CO, Palencia Luaces R. Study of the prevalence of epilepsy among school children in Valladolid, Spain. Epilepsia. 1991; 32: 791-797. doi: 10.1111/j.1528-1157.1991.tb05535.x.

40) Forsgren, L, Beghi, E, Oun A, Sillanpaa M. The epidemiology of epilepsy in Europe - a systematic review. Eur J Neurol. 2005; 12: 245-53. doi: 10.1111/j.1468-1331.2004.00992.x. PMID: 15804240.

41) Berkovic SF, Howell RA, Hay DA, Hoppaer JL. Epilepsies in twins: genetics of the major epilepsy syndromes. Ann Neurol. 1998; 43: 435-45. doi: 10.1002/ana.410430405. PMID: 9546323.

42) Vadlamudi L, Andermann E, Lombroso CT, Schachter SC, Milne RL, Hopper JL, et al. Epilepsy in twins: insights from unique historical data of William Lennox. Neurology. 2004; 62: 1127-33. doi: 10.1212/01.WNL.0000118201.89498.48. PMID: 15079012.

43) Ottman R, Lee JH, Risch N, Hauser WA, Susser M. Clinical indicators of genetic susceptibility to epilepsy. Epilepsia. 1996; 37: 353-61. doi: 10.1111/j.1528-1157.1996.tb00571.x. PMID: 8603640. 